\title{
Tourism, Environment and Energy: An Analysis for China ${ }^{1}$
}

\author{
Arshian Sharif \\ Othman Yeop Abdullah Graduate School of Business \\ Universiti Utara Malaysia \\ Sintok, Malaysia \\ Department of Business Administration \\ Eman Institute of Management and Sciences \\ Karachi, Pakistan \\ E-mail: arshian.aslam@gmail.com
Shrabani Saha
Lincoln International Business School
University of Lincoln
Lincoln, United Kingdom.
Email: $\underline{\text { ssaha@lincoln.ac.uk }}$ \\ Neil Campbell \\ Bond Business School \\ Bond University \\ Cold Coast, Australia \\ Email: ncampbel@bond.edu.au

\begin{abstract}
Avik Sinha
Department of General Management and Economics

Goa Institute of Management, India.

Email: $\underline{\text { f11aviks@,iimidr.ac.in }}$
\end{abstract}

\author{
Dalia M. Ibrahiem \\ Faculty of Economics and Political Sciences \\ Cairo University, Egypt \\ E-mail: daliaharby@feps.edu.eg
}

\footnotetext{
${ }^{1}$ Running title: "Tourism, Environment and Energy". Corresponding author: Neil Campbell ncampbel@,bond.edu.au +61 (07) 55951557.
} 


\section{Tourism, Environment and Energy: An Analysis for China}

Abstract: International tourism as a cause of global warming is a controversial and topical issue. Here, we use the novel Morlet Wavelet time-frequency approach to gain a deeper insight into the dynamic nexus between tourism, renewable energy utilization, energy utilization and carbon dioxide emissions for China using annual data over the era 1974-2016. The techniques we use include Continuous Wavelet power spectrum, the Wavelet Coherency, and the Partial and the Multiple Wavelet Coherence for time-frequency decomposition that can capture local oscillatory components in time series. Our findings support the hypothesis that tourism can cause increased energy utilization and carbon dioxide emissions in China, which challenges the sustainable tourism development goal. However, on the positive side, the relationship between tourism and renewable energy utilization is shown to facilitate reduced environmental degradation in the medium-long run.

Keywords: Energy utilization; renewable energy; $\mathrm{CO}_{2}$ emission; tourism; partial and multiple wavelet coherence; country study

JEL: Q32; Q35; Q53; Z30; Z32 


\section{Introduction}

On one hand, international tourism is seen as an important engine for generating growth and employment in developing countries. On the other hand, it is seen as a contributor to global warming particularly with regard to the carbon dioxide $\left(\mathrm{CO}_{2}\right)$ emissions from aircraft, cruise ships and accommodation construction etc. Tourism is estimated to account for $5 \%$ of global carbon emissions (Solarin, 2014; and Othman, Mohamed, \& Aziz, 2012). We need to be careful about concluding that a simple trade off exists here. During the earlier stages of economic growth, nations rely more on fossil fuel-based energy solutions, as this energy solution is cost effective. However, the fossil fuel-driven growth trajectory results in ambient air pollution through greenhouse gas emissions, of which $\mathrm{CO}_{2}$ holds a major share. A gradual rise in these emissions poses a threat to the health of the labour force, and thereby, jeopardizing the growth trajectory. As a means of sustaining economic growth, nations need to retain the quality of the environment, and in pursuit of retaining environmental quality, policymakers start investing in renewable energy projects. Hence, the objective of sustainable economic growth strongly motivates investment in renewable energy projects. To gain insights into this complex issue, our paper, using China as a case study, explores the dynamic association between the following variables: tourism, renewable energy utilization, fossil fuel energy utilization, and $\mathrm{CO}_{2}$ emissions. With China, its vast tourism industry and substantial effect on global warming, makes it an obvious choice. Since the relationship between these variables is complex and ambiguous, we take the Morlet Wavelet timefrequency approach. This allows us to look for evidence of a causal relationship between tourism demand and $\mathrm{CO}_{2}$ emissions, and, to explore the mitigating effects of renewable energy on tourism.

The Chinese tourist industry has rapidly expanded since the economic reform in the late seventies. According to the World Travel and Tourism Council Report (WTTC, 2018), China 
ranks second after the United States in terms of the size of travel and tourism, as a contributor to GDP. During 2017, this sector contributed US\$402.3 billion directly to Chinese GDP, it generated $28,250,000$ jobs and it is predicted that the employment in the tourism sector will grow by $1.5 \%$ in 2018, with international tourist arrivals expected to be $63,539,000$. The growth prospects for the tourism industry are very strong with a forecasted increase of $1.8 \%$ per annum in the upcoming ten years (WTTC, 2018). With the increase in China's tourism and the use of energy by this sector, its impact on the environment is a matter for concern. Shuxin, Genxu, \& Yiping (2016) show that tourism-induced energy utilization in China has increased from 178.21 PJ to $565.82 \mathrm{PJ}$ between 1994-2013, and during the same era, the $\mathrm{CO}_{2}$ emissions from tourism-induced transport have increased from 14.96 Mt to 47.94 Mt. This increase has been attributed to the rise in per-person distance for every trip, along with the number of trips. Using a carbon-input-output table, Tang and $\mathrm{Ge}$ (2018) show that the carbon footprint of tourism in China is more than 20 per cent of total $\mathrm{CO}_{2}$ emissions. ${ }^{2}$ Using a similar methodological approach, Li, Li, Tang, \& Wang (2019) have estimated the nearly 39 per cent of the $\mathrm{CO}_{2}$ emissions from the transport sector are caused by tourism-related activities. In 2012, 25.70 per cent of the total $\mathrm{CO}_{2}$ emissions in Beijing were caused by tourism-related activities (Beijing Municipal Bureau of Statistics, 2014). Wu and Shi (2011) state that utilization of energy and its effect on the atmosphere upsurge synchronously with China's growing tourism. To accomplish the strategic objective of environmental sustainability along with tourism development, it is important to follow the strategic paths which respect the environment as well as ensure optimal economic benefits from tourism. Gössling, Scott, and Hall (2013) argue that all sectors, including tourism, need strong mitigation for the associated greenhouse gas

\footnotetext{
${ }^{2}$ Since the China Energy Statistics Yearbook does not contain any particular information on tourism-induced energy use, we have considered the estimations of different researchers in this area (see Tang et al., 2014; Chen, Thapa, \& Yan, 2018).
} 
emissions (GHG) so as to achieve the objective of reducing global emissions by $80 \%$ from the current level by 2050 .

The search for cheap and secure energy sources by the developed and energy dependent countries has raised the demand for alternative energy sources (alternatives to fossil fuels) for dealing with global warming and GHG emissions. The role of renewable energy in sustainable energy supply and reductions of carbon emissions has been widely acknowledged in the last ten years (Ocal \& Aslan, 2013). The threat of extinction of fossil fuels and increasing concerns regarding $\mathrm{CO}_{2}$ emissions and global warming have helped in the emergence of renewable energy sources. Renewable energy is the fastest growing source of energy in the world, its utilization has been increasing at an average of $2.3 \%$ per year since 2015 and this is expected to continue until 2040 (EIA, 2017). This increase in utilization of renewable energy sources includes wind energy, biomass energy, hydropower energy, waste energy and geo-thermal energy. China has started adopting the strategy of using renewable energy for dealing with issues of climate change and sustainable energy supply and is becoming a leading investor in this sector.

We examine the dynamic connection between tourism, renewable and fossil fuel energy utilization, and $\mathrm{CO}_{2}$ emanations for ascertaining sustainable tourism development in China. Over the years, China has turned out to be a highly popular tourism destination, and in order to facilitate tourism in China, policymakers are relying on the transport sector. Now, this sector is largely dependent on the fossil fuel-based energy and hence the associated negative environmental implications. In terms of $\mathrm{CO}_{2}$ emissions from tourism, China stands second in the world (Lenzen et al., 2018). In a recent study carried out on the Yangtze River Delta, it was found that the tourismrelated energy utilization increased by 3.57 times and tourism-associated $\mathrm{CO}_{2}$ emissions increased by 3.19 times between 2001 and 2015 (Chen, Thapa, \& Yan, 2018). Moreover, the following issues 
have now become important in China: emergence of ecotourism, and, the accelerated depletion of natural resources associated with tourism (this latter situation can be attributed to the existing transportation architecture (UNEP, 2008)). These concerns gradually diminished the acceptability of fossil fuel-based energy solutions and increased the demand for renewable energy solutions in the tourism sector in China. As a result of this situation, the 13th Five-Year Plan for Tourism Development of Beijing is focused on promoting clean energy-driven vehicles for the purpose of tourism (UNWTO, 2018). Because of these developments in China, we aim to assess the links between tourism, renewable and fossil fuel energy utilization, and $\mathrm{CO}_{2}$ emanations in China.

Next, following, Aguiar-Conraria, Azevedo, and Soares (2008) and Aguiar-Conraria, and Soares (2011), we investigate the dynamic associations by applying innovative Continuous Wavelet power spectrum and Wavelet Coherence techniques, which decompose time-frequencies of the variables being studied. Also, using the wavelet tools, we identify the changes both over time and differences across frequencies in tourism and energy variables within a unified framework. The wavelet power spectrum, in particular, can be easily adapted to consider the timevarying features at each erratic component that has not been apprehended so far. Besides, we employ Partial and Multiple Wavelet Coherence techniques to assess the association among the model parameters. These techniques assess the wavelet coherence across diverse temporal domains subsequent to adjusting conjoint factors and explanatory power of model parameters $(\mathrm{Ng}$ \& Chan, 2012). Owing to the convolution of the association, partial and multiple wavelet coherence techniques can advocate comprehensive conclusions concerning the associations in the frequency domain.

We contribute to the tourism economics literature through several dimensions: (a) considering the sustainable tourism in China, this study bring together the perspective of 
sustainable energy and environmental policies, which has hardly been considered in the literature, (b) the association between tourism, renewable and fossil fuel energy utilization, and $\mathrm{CO}_{2}$ emission has been analyzed in the frequency domain by localized oscillatory components in the time-domain region (Aguiar-Conraria et al., 2008), and thereby, overriding the shortcomings of the basic time-

series analysis, (c) the choice of Morlet Wavelet enables us to harvest "information on the amplitude and phase, both essential to study synchronism between different time-series" (AguiarConraria \& Soares, p. 648, 2011), and (d) by means of the lead-lag movement divulged through wavelet analysis, we are able to analyze the trajectory of the associative movement among the model parameters.

The remainder of the paper is set out as follows. The next section elaborates on the existing literature. The third section explains the model framework and data. The fourth section discusses the results and findings. The final section concludes with a discussion of policy implications.

\section{Literature Review}

The existing empirical literature on $\mathrm{CO}_{2}$ emission and economic development finds an association between $\mathrm{CO}_{2}$ emission, economic growth and energy utilization (Aslanidis \& Iranzo, 2009; Apergis \& Payne, 2010; Ozturk, 2010; Shahbaz \& Sinha, 2019). On the other hand, world-wide tourism has enjoyed an above-average growth rate, at around 4\% per year, for the last eight straight consecutive years (UNWTO, 2017). Obviously, it has the potential to substantially increase energy utilization and $\mathrm{CO}_{2}$ emission. However, the actual effect upon global warming is going to be critically dependent upon the use of renewable energy; hence this literature is also discussed below.

\subsection{Non-renewable energy utilization and Carbon dioxide emissions}

Non-renewable energy utilization is considered one of the most vital determinants of $\mathrm{CO}_{2}$ emissions. Several researches examine the connection between non-renewable energy utilization 
and $\mathrm{CO}_{2}$ emanations. As, Say and Yucel (2006) find a significantly encouraging connection between energy utilization and $\mathrm{CO}_{2}$ emanation in Turkey. Jalil and Mahmoud (2009) examine the association between energy utilization, income, trade openness and $\mathrm{CO}_{2}$ emanations in China during 1975-2005 and find a similar story. Various studies confirm this positive connection between utilization of energy and $\mathrm{CO}_{2}$ emanations such as Apergis and Payne (2009), Niu, Ding, Niu, Li, and Luo (2011), Jayanthakumaran, Verma, and Y. Liu (2012), Shahbaz, Khraief, Uddin, and Ozturk (2014), Tang and Tan (2015), Ibrahiem (2016), and Riti, Song, Shu and Kamah (2017).

Several studies that consider the causal relationship between energy utilization and $\mathrm{CO}_{2}$ emissions find inconclusive results. Some finds a bidirectional causal relationship such as Apergis and Payne (2009), Alam, Begum, Buysse, Rahman, and Huylenbroeck et al. (2011), and Shahbaz, Farhani, and Ozturk (2015). In contrast, other studies find a single directional causal connection from energy utilization to $\mathrm{CO}_{2}$ emanations such as Zeshan and Ahmed (2013), Alshehry and Belloumi (2015), and Shahzad, Kumar, Zakaria and Hurr (2017). In addition, a unidirectional causal relationship from $\mathrm{CO}_{2}$ emissions to energy utilization is found in other studies as such Lean and Smyth (2010). Also, Batool et al. (2019) examine the dynamic connection between energy utilization and carbon emanation in South Korea; the results of wavelet coherence confirm that energy utilization significantly increases carbon emanation in the country.

\subsection{Renewable energy utilization and Carbon dioxide emissions}

Some of the literature, for example Sebri and Ben-Salha (2014) focus on renewable energy utilization as an important determinant that can mitigate greenhouse gas emissions and $\mathrm{CO}_{2}$ emissions in particular. Most of these studies examine the relationship between $\mathrm{CO}_{2}$ emissions and renewable energy utilization and conclude that a negative relationship holds, i.e. an increase in renewable energy utilization reduces $\mathrm{CO}_{2}$ emissions; notably: Chiu and Chang (2009), Bilgili, 
Koçak, and Bulut (2016), Zoundi (2017), and Álvarez-Herranz, Balsalobre-Lorente, Cantos, and Shahbaz (2017). However, some of this literature finds mixed results such as Sebri and Ben-Salha (2014). Some other studies consider the relationship between renewable utilization of energy, nonrenewable utilization of energy and $\mathrm{CO}_{2}$ emanations. Al-Mulali Fereidouni, and Mohammed (2015) examines the relationships between renewable electricity utilization, non-renewable electricity utilization, capital, labour, exports, imports and $\mathrm{CO}_{2}$ emissions in Vietnam for the era 1981-2011 and finds that non-renewable electricity utilization contributes to $\mathrm{CO}_{2}$ emanations whereas, renewable electricity utilization has no effect on it. Moreover, Ben-Jebli and BenYoussef (2015) find a positive association between non-renewable utilization of energy and $\mathrm{CO}_{2}$ emanations and a negative relationship between renewable utilization of energy and $\mathrm{CO}_{2}$ emanations. Dogan and Seker (2016) investigate the relationship between renewable energy utilization, non-renewable energy utilization, trade openness, real income and $\mathrm{CO}_{2}$ emissions for European Union Nations over the era 1980-2012 and they conclude that there exists a negative connection among $\mathrm{CO}_{2}$ emissions and renewable utilization of energy, and there exists a encouraging relationship between non-renewable utilization of energy and carbon emanations. Bento and Moutinho (2016) find a negative relationship between renewable electricity utilization and emanations of $\mathrm{CO}_{2}$ in Italy. Dogan and Ozturk (2017) examine the relationship between renewable and non-renewable utilization of energy, real income and $\mathrm{CO}_{2}$ emanations for the USA and they confirm the existence of a positive association between non-renewable utilization of energy and $\mathrm{CO}_{2}$ emanations and a negative connection between renewable utilization of energy and carbon emanations. Similar results are reached by Sinha, Shahbaz, and Balsalobre (2017) for $\mathrm{N}-11$ countries. 


\subsection{Renewable/non-renewable energy utilization, tourism development and Carbon dioxide}

emissions

As we have discussed earlier, the tourism sector depends on fossil fuel-based energy utilization mainly to facilitate traveling and accommodation. Heavy reliance on this type of energy can contribute to $\mathrm{CO}_{2}$ emissions, thus usage of renewable energy resources by the tourism sector can mitigate such emissions (Isik \& Magdalena, 2017). The importance of tourism and its recognized impact on generating employment and income in various countries have stimulated work on analyzing its relationship with either non-renewable/renewable energy utilization or $\mathrm{CO}_{2}$ emissions or both. However, the results are inconclusive. For instance, Liu, Lai, and Kuok (2012) find a bidirectional causal relationship between energy utilization and tourism development with regard to Taiwan. Similar results are reached by Tiwari, Ozturk, and Aruna (2013) for OECD countries; and Sekrafi and Sghaier (2018) in Tunisia.

Kuo, Liu, and Lai (2012) conclude that tourism receipts might increase energy utilization and $\mathrm{CO}_{2}$ emissions in China. In contrast to this, Lee and Brahmasrene (2013) find that tourism may decrease $\mathrm{CO}_{2}$ emissions for a panel of European Union countries, and similar results are found by Katircioglu (2014) with regard to Singapore. Zaman, Khan, and Ahmad (2011) find a unidirectional causal relationship stemming from tourism to $\mathrm{CO}_{2}$ emissions. Similar results are found by Zhang and Gao (2016) in eastern China and Raza, Sharif, Wong, and Abd Karim (2017) in the USA. Additionally, Katiricioglu (2014) confirms the contribution of tourism development to both energy utilization and $\mathrm{CO}_{2}$ emissions in Turkey. Dwyer, Forsyth, Spurr, and Hoque (2010) find that tourism contributes to greenhouse gas emissions in Australia. Also, León, Arana, and Hernández-Alemán (2014) find that although tourism development contributes to environmental degradation in both developed and less developed countries, its effect is less in less developed 
countries. Similar results are found by Solarin (2014), Robaina-Alves, Moutinho, and Costa (2016), Sharif, Afshan, and Nisha (2017), Zaman, Shahbaz, Loganathan, and Raza (2016) and Dogan, Seker, and Bulbul (2017). Moreover, Ozturk (2016) referring to a panel of 34 developed and developing countries finds that there is a positive relationship between $\mathrm{CO}_{2}$ emissions and tourism indicators and a negative relationship between energy utilization and tourism indicators. As for Paramati, Shahbaz, and Alam (2017), they find that tourism decreases environmental degradation in western European Union countries while it increases it in eastern European Union countries. Also, mixed results are found by Isik, Doğan, and Ongan (2017) for the causality relationship between energy utilization and tourist arrivals and receipts for the top-most visited countries. Moreover, Mishra et al. (2019) examine the association between tourism and carbon emanations in the USA by applying different wavelet methods i.e. partial and multiple wavelet. The results confirm that tourism development is one of the available measures for reducing environmental degradation in the US economy.

As mentioned above, renewable energy utilization is now a vital determinant that can mitigate environmental degradation, but there are a limited number of studies that are concerned with the relationship between tourism development and renewable energy utilization. This stream of literature is yet to reach any clear conclusions. Among these studies, Ben-Jebli, Ben-Youssef, and Apergis (2014) find that tourist arrivals and renewable energy utilization mitigate $\mathrm{CO}_{2}$ emissions for Central and South America, and they confirm the bidirectional causal relationship between tourist arrivals and environmental degradation. Isik, Dogru, and Turk (2017) conclude that there is a unidirectional causal relationship from tourist arrivals to renewable energy utilization in Italy, Spain, Turkey and USA, and unidirectional causality from renewable energy utilization to tourist arrivals in China and no causality in France and Germany. 
The above-mentioned studies use various methodologies including ARDL model, Johansen cointegration model, Generalized Method of Moments, panel cointegration, OLS, FMOLS, Pedroni and Kao panel co-integration techniques, wavelet transform framework, vector error correction model, etc. So far findings are mixed due to different methodologies used, variables used, and time eras chosen. Moreover, the effect of renewable energy utilization on tourism development is not clear as there are very few studies that investigate this relationship.

\section{Data and methodology}

\subsection{Model}

This study aims to assess the association between tourism, renewable and fossil fuel energy utilization, and $\mathrm{CO}_{2}$ emissions in China utilizing frequency domain analysis. While analyzing this association, we are interested in understanding the nature of co-movement among these variables, and not just their long run coefficients. In doing so, we need to confirm their long run cointegrating association in the time domain, as the tests confirming this association are the diagnostic tests for assessing the co-movement among these variables. The question of including other variables might arise in this pursuit, and we need to explain the reason for not considering other variables. In keeping with the objective of this study, we need to assess the association of these variables mainly through co-movement, and not through assessing long run coefficients. Hence, adding additional explanatory variables would not have any impact on the estimation results. Therefore, the estimation process considers only four variables: tourism, renewable and fossil fuel energy utilization, and $\mathrm{CO}_{2}$ emissions.

In keeping with the research objective, we hypothesize that there is a possible comovement between tourism, renewable energy utilization, fossil fuel energy utilization, and $\mathrm{CO}_{2}$ emissions for China in the frequency domain. 


\subsection{Data}

The main variables include tourist arrivals (TOR), renewable energy utilization (RENEW), energy utilization $(\mathrm{ENC})$ and $\mathrm{CO}_{2}$ emissions $\left(\mathrm{CO}_{2}\right)$ and all variables are in annual frequency ranging from 1974-2017. TOR is measured by the number of tourist arrivals per year in the country during the study era. Renewable energy utilization is measured in kilotons and energy utilization is considered as the quantity of total primary energy utilized. It is calculated in kilogram oil equivalent. Finally, $\mathrm{CO}_{2}$ as an alternate for degradation of environmental is calculated as the whole emission of carbon dioxide and is calculated in kilotons. The information for all the factors except renewable energy, are obtained from the World Bank (World development indicator). Renewable energy data is collected from National Bureau of Statistics, China. It is converted into natural logarithm of difference series in order to acquire the return-series to make our conclusion more comparable. The time era is selected by the availability of data and to assure that data for all the variables under study is complete for the era 1974-2016. Aloui, Hkiri, Hammoudeh, and Shahbaz (2018) conducted a similar analysis with annual data from 1969-2014 for the oil price, inflation, exchange rate, and economic growth nexus in Saudi Arabia.

\subsection{Methodology}

We employ different methods of Wavelet analysis in order to examine the linkage among tourism, energy utilization, renewable energy utilization and carbon dioxide emission. Essentially, this is explained essentially by the ability of these methods to focus and follow the varying outlines of time scale. In fact, the Wavelet technique allows the prediction of time series' spectral features as being a time function and also an explanation of the variation over time of time series' erratic components. In particular, we can use Continuous Wavelets, Coherence of Wavelet, Multiple Wavelet Coherence and Wavelet Power. In addition, Ruan and Nunes (2009) argue that the 
technique of cross wavelets has the ability to decompose in the first time and reconstruct in the second time the following function:

$x(\mathrm{t})=1 / \mathrm{C}_{\psi} \int_{0}^{\infty}\left[\int_{-\infty}^{\infty} \mathrm{Wx}(\mathrm{u}, \mathrm{s}) \psi_{\mathrm{u}, \mathrm{s}}(\mathrm{t}) \mathrm{du}\right] \mathrm{ds} / \mathrm{s}^{2}, s>0$

The efficiency of the approach of Wavelet Coherence is due to its measurement of the coefficient across series of localized correlation especially in the domain of time-frequency. By the way, the Wavelet method coherence is measured through dividing the smoothed CWS' absolute value by the WPS of smoothed individual product for each series.

$\mathrm{R}^{2}(\mathrm{u}, \mathrm{s})=\frac{|S(s-1 W x y(u, s))|^{\wedge} 2}{\left(S\left(s-\left.1 W x(u, s)\right|^{\wedge} 2\right) S\left(s-1 W y(u, s)^{\wedge} 2\right)\right.}$

After employing both techniques such as Wavelet Coherence and Cross-Wavelet, we may apply for the methods of Multiple and Partial Wavelet. Particularly, these two methods contribute in the inclusion of control variables in a multivariate framework. However, this is not possible via both coherency approaches of wavelet and wavelet coherence. We can thus detect the impact of control variables on carbon dioxide emission. Moreover, in the framework of a bivariate wavelet and in order to avoid series 'comparison, we use the methods of Partial and Multiple Wavelet Coherency. Some authors suggested that these methods eliminate the bias of oscillations' low frequency, which exists frequently in the prediction of the power spectrum of the wavelet approach (Liu, Liang, \& Weisberg, 2007; Veleda, Montagne, \& Araujo, 2012). We should note that the techniques of a Multivariate Wavelet add a new variable which is considered a third variable and also a conditioning factor. Besides, the difference between Partial and Multiple Wavelet Coherence methods is that the partial investigates the two variables' influences on a third one, but the second wavelet method is considered more akin to a various association, which is thus applied for testing the impact of many independent variables on a single ene platform. 
The following expression presents the approach of the specific method of Partial Wavelet Coherence (PWC). It allows the identification of the Wavelet Coherence (WC) among both series $\left(y, x_{1}\right)$ after deleting the third series $\left(x_{2}\right)$ impacts. The expression of the current function is shown as follows:

$\mathrm{RP}^{2}\left(\mathrm{y}, \mathrm{x}_{1} \mathrm{x}_{2}\right)=\frac{|R(y, x 1)-R(y, x 2) \cdot R(y, x 1)| *^{\wedge} 2}{[1-R(y, x 2)]^{\wedge}[1-R(x 2, x 1)]^{\wedge} 2}$

By using PWC technique, we may employ Multiple Wavelet Coherency (MWC) approach. The latter is identical to the multiple associations. In order to predict the coherence of many variables on a dependent ene variable, we use the MWC, which has the power to examine this linkage. The model function of multivariate wavelet coherence function is presented as follows:

$\mathrm{RM}^{2}\left(\mathrm{y}, \mathrm{x}_{2} \mathrm{X}_{1}\right)=\frac{R 2(y, x 1)+R 2(y, x 2)-2 R e[R \cdot(y, x 1) \cdot R(y, x 2) * R(x 1, x 2) *}{1-R 2(x 1, x 2)}$

\section{Empirical results}

This section discusses the data analysis focusing on the dynamic relationship between tourism, energy utilization, renewable energy utilization and $\mathrm{CO}_{2}$ emissions evidence from China. The main objective of this study is to consider the relationship between tourism, renewable energy utilization, energy utilization and $\mathrm{CO}_{2}$ emission in China. Prior going towards data analysis, the time series of our factors are transformed into natural logarithmic series. The purpose behindhand the transformation of original series into logarithmic is because we are assuming the information that outcomes are more effective in returns relatively than original and raw values (Tiwari, Bhanja, Dar, \& Islam, 2015). Fig. 1, plots the actual as well as log-transformed difference time series data for all the variables under study. It can be observed that the actual series appears to be nonstationary, whereas converted first difference of all the series seems to be stationary. Moreover, all the actual series demonstrates rising trends. 


\section{$<$ Insert Figure 1 here $>$}

Conversely, substantial fluctuations can be seen in the real difference series indicating that there exist significant changes in all the variables under the study and for the entire study era. The descriptive statistics and correlation matrix for the factors are displayed in Table 1 . The $\mathrm{CO}_{2}$ emission and renewable energy utilization show the highest and the lowest standard deviation, respectively. All the series have accepted the Jarque-Bera test and confirm that they are not normally distributed, which indicates a presence of nonlinearity among the dataset. In this situation time-frequency methodology which accounts for nonlinear relationship is ideal (Sharif \& Afshan 2016; Sharif et al. 2017; Afshan et al. 2018; Raza et al. 2019; Mishra et al. 2019b; Sharif, Afshan \& Qureshi, 2019; Sharif, Shahbaz \& Hill, 2019; Arain et al. 2019). Furthermore, the correlation matrix shows significant relationships between the variables.

\section{<Insert Table 1 here $>$}

\subsection{Continuous Wavelet Transform}

Continuous Wavelet power spectrum results for TOR, RENEW, ENC and $\mathrm{CO}_{2}$ emission for China are displayed in Fig. 2. The horizontal axis measures the time era depicting five-years in progression from 1974-2016. The Y-axis measures the erratic cycle say 0-4, 4-8 etc. The direction of $\mathrm{Y}$-axis is in reverse scale, i.e., closer to the $\mathrm{Y}$-axis represents more long-term scale. It can be seen that in the case of TOR, there are patterns of strong variance in small-medium runs. As for RENEW and ENC, the high variation is noticeable in small scales, but not in medium and long runs, while $\mathrm{CO}_{2}$ emanations has a robust variation in the long run (lower panel, right, Fig. 2). TOR mostly exists in small time scales during 1981-1985 and also for medium scales in between 19851990. However, for the entire study era, high-scale variance seems to be almost non-existent. Alternatively, inbound tourism is a bit volatile in the short-medium run, but the stability remains 
in the long-run. In the cases of RENEW and ENC, a strong variance exists in eras 0-4 yearly cycles during 2010-2015. As for $\mathrm{CO}_{2}$ emanations, a strong variation can be observed in the long run during 1985-2005. These outcomes suggest that TOR, RENEW, ENC show more variance in the medium-run, but $\mathrm{CO}_{2}$ emanations has a significant variation in the medium-long run. Also, the common islands between the two series exist during 1980-1985 for TOR and $\mathrm{CO}_{2}$ emission and later 2010-2015 for RENEW and ENC (Fig. 2). The relationship between the described patterns in the bivariate relationship using continuous wavelet transform (Fig. 2) is not very clear and comprehensible. Moreover, the connections between the patterns are low, hence, further investigation is performed using wavelet coherence.

\section{$<$ Insert Figure 2 here $>$}

\subsection{Wavelet Coherence}

The results of the bivariate relationship between the variables using wavelet coherence are presented in Fig. 3. The WC finds the sections in time-frequency domain where two time series co-moves. Fig. 3 provides some motivating results. The findings of Wavelet Coherence for TORRENEW display that in the era of 0-4 years cycle in 2012 onwards, the pointers are right-side-up describing that the variables are in-phase showing cyclic impact with RENEW as leading variable suggesting that renewable energy utilization can predict the number of international tourists flowing into the country. Renewable energy utilization (RENEW) is the leading variable in this co-movement, and thereby, it can act as a movement predictor for the TOR, which is the tourist arrivals. The result for TOR with ENC and $\mathrm{CO}_{2}$ (upper panel) emission is quite similar, revealing that in the era of 4-8 years in 1985-1990, the pointers are left-side-up suggesting that the variables are out-phase and indicating an anti-cyclic impact with $\mathrm{ENC}$ and $\mathrm{CO}_{2}$ lagging. It indicates that ENC and $\mathrm{CO}_{2}$ emission tend to have delayed reactions to a change in international tourist flows. 
The RENEW-ENC results are that in the era of 0-4 cycle during 2000-2007, the pointers are leftside-up indicating that ENC-RENEW is out-phase showing anti-cyclic impact with ENC lagging. Moreover, the results of RENEW-CO $\mathrm{CO}_{2}$ emission suggest that in the era of $0-4$ year cycle during 2009-2013, the pointers are left-side-down explaining that the variables are out-phase and showing anti-cyclic impact with $\mathrm{CO}_{2}$ is lagging. Alternatively, the level of $\mathrm{CO}_{2}$ emission depends on the changes in the renewable energy utilization. Finally, the result of ENC- $\mathrm{CO}_{2}$ emission shows that 4-16 years cycle during 1985-2015, the pointers are mostly right-side-up explaining that ENC$\mathrm{CO}_{2}$ emission is in-phase displaying a cyclic impact with $\mathrm{CO}_{2}$ emission leading, which indicates that fossil fuel energy utilization can predict the future changes in the level of $\mathrm{CO}_{2}$ emission. Overall, the results of Wavelet Coherence reveal that tourism is influenced by renewable energy utilization. Moreover, renewable energy utilization can lower carbon emission and increase international tourist flows in the short-medium run for sustainable development in China. Conversely, tourism can influence ENC and $\mathrm{CO}_{2}$ in China.

\section{$<$ Insert Figure 3 here $>$}

\subsection{Partial Wavelet Coherence}

This subsection presents the results of partial and multiple wavelet coherence where, PWC is the partial wavelet coherence findings (left-panel, Fig. 4), and MWC describes the multiple wavelet coherence graphs (right-panel) between tourism, energy utilization, renewable energy utilization and $\mathrm{CO}_{2}$ emission in China. Fig. 4a reports the partial wavelet coherence between energy utilization and renewable energy utilization after excluding the emission of $\mathrm{CO}_{2}$. The association is found to be weak and only one red color significant region is recognized during 2011-2013, for 4-8 years cycle (medium-run horizon). However, when considering $\mathrm{CO}_{2}$ emission in the ENCRENEW relationship (Fig. 4b), a comparatively different condition is observed. A strong co- 
movement is noticed for both medium and high-frequency bands during the entire sample era. Predominantly, in the short-run, one island from 0-4 years cycle, where the correlation ranges from 0.9-1.0 (strong correlation) is noticed. In the medium-long run, the existence of single island in entire 4-8- and 8-16-year cycles is identified, with the correlation ranging from 0.8-1.0. Overall, the PWC and MWC confirm a strong and robust impact of $\mathrm{CO}_{2}$ emission in investigating the connection between RENEW and ENC in China. The results are also consistent with the pair-wise Granger causality test, verifying the existence of causality running from ENC to RENEW and from RENEW to $\mathrm{CO}_{2}$ emission.

\section{$<$ Insert Figure 4 here $>$}

Fig. $4 c$ shows the partial wavelet coherence between energy utilization and renewable energy later stopping out the tourism impact. The coefficient of correlation is observed to be weak and only one yellow color significant island is identified in the 0-4 years cycle (short-run horizon) during 2002-2004. Then, when seeing tourism in the connection between ENC and RENEW (Fig. 4d), a robust co-movement in short-medium phase is noticed. In the $0-4$ year era, we observed the existence of three areas in 1987-1991, 1997-2005 and 2011-2013 era, where the coefficient of correlation ranges between 0.7- 0.9. However, in the medium run, there is a solid co-movement between RENEW, ENC and TOR. In the 4-8 year cycle, one strong red island is observed in 19821986 with the correlation ranging from $0.7-0.8$. The results are also consistent with the pair-wise Granger causality test, signifying the existence of causality running from ENC to RENEW and from RENEW to TOR in China. The results are consistent with the results of wavelet coherence that renewable energy influences inbound tourism in the short-medium run, but there is no impact in the long-run. 
Figs. $4 \mathrm{e}$ and $4 \mathrm{~g}$ illustrate the partial wavelet coherence between RENEW and $\mathrm{CO}_{2}$ emission canceling out ENC and TOR, respectively. The coefficient of correlation is observed to be weak and only one small red color significant island is recognized in a 0-4 years cycle during 2008-2010 (cancelling out ENC) and 2006-2009 (cancelling out TOR). However, when seeing ENC and TOR, in the association between RENEW and $\mathrm{CO}_{2}$ emission (Figs. $4 \mathrm{f}$ and $4 \mathrm{~h}$ ), a strong co-movement is observed in the short-medium run of RENEW, $\mathrm{CO}_{2}$ emanations and ENC. In the 0-4- and 4-8-year cycles, we detected the presence of two red areas in 1989-1991 and 2003-2011, where the value of correlation ranges between $0.7-0.9$. In Fig. 4h, from the $0-4-$ and 4-8-year cycles, we found the presence of three red islands during 1986-1991 and 2006-2012 in the short-run and from 19811986 in the medium-run, where the value of correlation ranges between 0.7-0.9. The results confirm the earlier findings (Wavelet Coherence) that tourism affects renewable energy utilization and carbon emissions in the short and medium run. The emergence of electric vehicles and vehicles run by clean energy sources are being implemented by the policymakers in various tourism destinations in China, and this move might increase the demand for renewable energy and decrease the level of $\mathrm{CO}_{2}$ emissions in the short run. This segment of the results might not hold true for the long run, as the gradual rise in tourist arrivals in these destinations might gradually increase the level of $\mathrm{CO}_{2}$ emissions through rise in the tourism-allied industrial activities and tourism related activities. In order to enhance the attractiveness of these destinations, these tourism-allied industrial sectors will be boosted through fossil-fuel energy utilization. In such a scenario, a long run association can be established through the intervention of tourism investment in pursuit of augmenting renewable energy utilization.

Figs. $4 \mathrm{i}$ and $4 \mathrm{k}$ show the partial wavelet coherence between TOR and $\mathrm{CO}_{2}$ emission canceling out ENC and RENEW, respectively. The correlation is found to be weak and only one 
small red color significant island is identified for the 4-8-year cycle during 1981-1987 (cancelling out RENEW), whereas no relationship is found between $\mathrm{TOR}$ and $\mathrm{CO}_{2}$ emission (cancelling ENC). The results suggest that tourism and $\mathrm{CO}_{2}$ emission are correlated. However, when considering ENC and RENEW, in the association between TOR and emanation of $\mathrm{CO}_{2}$ (Fig. $4 \mathrm{j}$ and 41 ), a solid fluctuation in the short-medium run is detected for RENEW, $\mathrm{CO}_{2}$ emission, and TOR. In the 0-4and 4-8 years era, the current study observed the presence of three red areas in 1987-1993 and 1997- 2001 in the short-horizon and during 1980-1986 in the medium-horizon, where the value of correlation ranges between $0.7-0.8$. In Fig. 4l, from the $0-4-$ and 4-8 years era, we observed the existence of two red areas in 1988-1990 in the short-run and from 1981-1989 in the medium-run, where the value of correlation ranges between $0.7-0.8$. It is evident that energy utilization and renewable energy utilization influence the correlation between TOR and $\mathrm{CO}_{2}$ emission.

Figs. $4 \mathrm{~m}$ and $4 \mathrm{o}$ display the PWC between ENC and $\mathrm{CO}_{2}$ emission excluding TOR and RENEW, correspondingly. The value of coefficient of correlation is found to be very strong and a one large red color significant island is recognized for 4-8- and 8-16 years era in the whole cycle era (cancelling out RENEW and TOR individually) illustrating the general concerns that ENC and $\mathrm{CO}_{2}$ emission are highly correlated. While considering TOR and RENEW, in the connection between $\mathrm{ENC}$ and $\mathrm{CO}_{2}$ emanations (Fig. $4 \mathrm{n}$ and $4 \mathrm{p}$ ), we identified a firm fluctuation in shortmedium-long run of RENEW, $\mathrm{CO}_{2}$ emanations, and TOR. In the $0-4$ year era, the current study observed a presence of one red island in 1986-1991 and in the 4-8 and 8-16 years era, we observed one large red area for an entire era where the connection value ranges between 0.8 to 0.9 . In Fig. $4 p$, from the 0-4 years era, the current study observed the existence of two red islands in 19881991 and 1996-2001 in the short run. In the 4-8 and 8-16 era, again we see one large red island for an entire cyclic era with the correlation value ranges from $0.8-0.9$. In other words, tourism and 
renewable energy utilization do affect the correlation between energy utilization and $\mathrm{CO}_{2}$ emission.

Figs. $4 \mathrm{q}$ and $4 \mathrm{~s}$ explain the Partial Wavelet Coherence between the sets: changes in TOR and ENC excluding RENEW and $\mathrm{CO}_{2}$ emission. The strong co-movement is located at the 4-8year cycle during 1981-1985 in a medium-run (cancelling out RENEW), whereas, a weak comovement is presented in the 0-4 year cycle during 1998-1999 (cancelling out $\mathrm{CO}_{2}$ emission). There is not much correlation between TOR and ENC, if RENEW and $\mathrm{CO}_{2}$ are excluded. When focusing on TOR and ENC in the relationship between RENEW and $\mathrm{CO}_{2}$ emission (Figs. 4r and 4t), we identify a strong co-movement in the short-medium year cycle where the value of the correlation ranges from 0.8-0.9 suggesting that RENEW and $\mathrm{CO}_{2}$ influence the relationship between TOR and ENC. Fig (4u) and (4w) display the PWC between TOR and RENEW excluding $\mathrm{CO}_{2}$ emanations and $\mathrm{ENC}$, respectively. The coefficient of correlation is found to be very robust and only one small red color substantial island is recognized during 1982-1987 (cancelling out $\mathrm{CO}_{2}$ emission and ENC individually) for the 4-8-year cycle (long run). The results confirm that TOR and RENEW are correlated in the medium run with the influences of $\mathrm{CO}_{2}$ and ENC. While seeing $\mathrm{CO}_{2}$ emanations and ENC, in the connection between RENEW and TOR (Fig. 4v and 4x), we identify a firm fluctuation in short and medium run of RENEW, $\mathrm{CO}_{2}$ emission, and TOR. In the 0-4-years era, the present research observed the presence of one red island during 1986-1991 and in the 4-8 year cycle, one large red island for 1981-1989 era is seen where the value of correlation ranges from $0.8-0.9$. In Fig. 4x, from the 0-4-year era, the study detected an existence of two red islands in 1986-1992 and 2011-2012 in the short-run. In 4-8 era, again one large red island for 1980-1988 era is seen, where the value of correlation ranges from 0.8-0.9. So, $\mathrm{CO}_{2}$ and ENC affect the TOR-RENEW relationship. Overall, the findings confirm that tourism is correlated 
with renewable energy and $\mathrm{CO}_{2}$ emission especially in the short-medium run, but the correlation disappears in the long-run. However, $\mathrm{CO}_{2}$ emission affects fossil fuel energy as well as renewable energy utilization in the long run. Since China is gradually moving towards the business of ecotourism, it is important for the policymakers to retain and improve the environmental quality of tourism destinations. Henceforth, the policymakers might try to implement renewable energy solutions by gradually replacing the fossil-fuel energy solutions, as the latter is responsible for the rise in $\mathrm{CO}_{2}$ emissions in the ambient atmosphere.

\section{Conclusion}

By far, we have evaluated the associative co-movement between tourism, renewable and fossil fuel energy utilization, and $\mathrm{CO}_{2}$ emission in China, by means of Wavelet Transform and Wavelet Coherence methods. This study contributes to our understanding of the way in which the associative movement between sustainable tourism and ecological sustainability in China changes its course along the frequency domains. For temporal domain, our results demonstrate heterogeneous association among the model parameters, whereas in frequency domain, the associations are both coherent and the model parameters are having lead-lag associations. The phase-wise outcomes show that these associative movements vary along the temporal domain for medium and short runs. Lastly, the results confirm the presence of significant association between the model parameters in the frequency domain through their lead-lag associations.

Also, the findings suggest that energy utilization and $\mathrm{CO}_{2}$ emission act as lagging indicators for tourism. In other words, international tourism increases the energy utilization and $\mathrm{CO}_{2}$ emissions. Given that China has experienced an estimated $288 \%$ increase in international tourist numbers over the 15-year era from 1995-2009 (Gössling et al., 2013), it is highly plausible that this tourism growth has not been environmentally sustainable. International tourism involves 
such a movement of people over long distances, as well as their accommodation and activities, the direct contribution to greenhouse gases is clearly going to be quite substantial.

So, the question arises: can China's tourist growth continue while, in overall terms, the emissions of $\mathrm{CO}_{2}$ associated with China decline? Here, our results are supportive of this outcome being possible. That is, our findings suggest that tourism and utilization of renewable energy facilitate reduced $\mathrm{CO}_{2}$ emissions in the short-medium run in China. Renewable energy acts as a leading indicator implying that converting energy utilization to renewable energy further enhances the international tourist flows and promotes sustainable tourism by lowering $\mathrm{CO}_{2}$ emission. This suggests that policy makers should make contingency plans for generating renewable energy to deal with the threat of global warming in the next two-to-three years and to promote tourism with an emphasis on sustainability.

As mentioned earlier, energy utilization in tourism, to a large extent, comes from transportation activities involving long distance air and sea travelling, hence, promoting a sectoral shift from long distance international tourism to domestic and regional tourism can moderate $\mathrm{CO}_{2}$ emission and hence global warming. Moreover, construction of accommodation including multistoried buildings is an energy intensive activity (Rossello-Batle, Moia, Cladera, \& Martinez (2010) point out the importance of recycling construction materials to counteract global warming). The implementation of clean technologies utilizing renewable energy for manufacturing and construction purposes and promoting eco-tourism for its sustainability has the potential to achieve the objectives of developing the tourist industry and reducing $\mathrm{CO}_{2}$ emission. 


\section{References}

Afshan, S., Sharif, A., Loganathan, N., \& Jammazi, R. (2018). Time-frequency causality between stock prices and exchange rates: Further evidences from cointegration and wavelet analysis. Physica A: Statistical Mechanics and its Applications, 495, 225-244.

Aguiar-Conraria, L., \& Soares, M. J. (2011). Oil and the macroeconomy: using wavelets to analyze old issues. Empirical Economics, 40(3), 645-55.

Aguiar-Conraria, L., Azevedo, N., \& Soares, M. J. (2008). Using wavelets to decompose the time frequency effects of monetary policy. Physica A: Statistical Mechanics and its Applications, 387(12), 2863-78.

Alam, M. J., Begum, I. A., Buysse, J., Rahman, S., \& Huylenbroeck, G. Y. (2011). Dynamic modelling of the causal relationship between energy consumption, $\mathrm{CO}_{2}$ emissions and economic growth in India. Renewable and Sustainable Energy Reviews, 15(6), 3243-51.

Al-Mulali, U., Fereidouni, H. G., \& Mohammed, A. H. (2015). The effect of tourism arrival on $\mathrm{CO}_{2}$ emissions from the transportation sector. International Journal of Tourism and Hospitality Research, 26(2), 230-43.

Aloui, C., Hkiri, B., Hammoudeh, S., \& Shahbaz, M. (2018). A Multiple and Partial Wavelet Analysis of the Oil Price, Inflation, Exchange Rate, and Economic Growth Nexus in Saudi Arabia. Emerging Markets Finance and Trade, 54(4), 935-56.

Alshehry, A. S., \& Belloumi, M. (2015). Energy consumption, carbon dioxide emissions and economic growth: the case of Saudi Arabia. Renewable and Sustainable Energy Reviews, $41,237-47$. 
Álvarez-Herranz, A., Balsalobre-Lorente, D., Cantos, J. M., \& Shahbaz, M. (2017). Energy Innovations-GHG Emissions Nexus: Fresh Empirical Evidence from OECD Countries. Energy Policy, 101, 90-100.

Apergis, N., \& Payne, J. E. (2009). $\mathrm{CO}_{2}$ emissions, energy usage, and output in Central America. Energy Policy, 37(8), 3282-86.

Apergis, N., \& Payne, J. E. (2010). Renewable energy consumption and growth in Eurasia. Energy Economics, 32(6), 1392-97.

Arain, H., Han, L., Sharif, A., \& Meo, M. S. (2019). Investigating the effect of inbound tourism on FDI: The importance of quantile estimations. Tourism Economics, DOI: $10.1177 / 1354816619859695$.

Aslanidis, N., \& Iranzo, S. (2009). Environment and development: is there a Kuznets curve for $\mathrm{CO}_{2}$ emissions? Applied Economics, 41(6), 803-10.

Batool, R., Sharif, A., Islam, T., Zaman, K., Shoukry, A. M., Sharkawy, M. A., ... \& Hishan, S. S. (2019). Green is clean: the role of ICT in resource management. Environmental Science and Pollution Research, 26(24), 25341-25358.

Beijing Municipal Bureau of Statistics (2014). Beijing Statistical Yearbook 2014. Available at: http://tji.beijing.gov.cn/nj/main/2014_tjnj/index.htm

Ben-Jebli, M., \& Ben-Youssef, S. (2015). "The environmental Kuznets curve, economic growth, renewable and non-renewable energy, and trade in Tunisia." Renewable and Sustainable Energy Reviews, 47, 173-85.

Ben-Jebli, M., Ben-Youssef, S., \& Apergis, N. (2014). The dynamic linkage between $\mathrm{CO}_{2}$ emissions, economic growth, renewable energy consumption, number of tourist arrivals and trade. MPRA Paper, No. 57261. 
Bento, J. P. C., \& Moutinho, V. (2016). $\mathrm{CO}_{2}$ emissions, non-renewable and renewable electricity production, economic growth and international trade in Italy. Renewable and Sustainable Energy Reviews, 55, 142-55.

Bilgili, F., Koçak, E., \& Bulut, Ü. (2016). The dynamic impact of renewable energy consumption on $\mathrm{CO}_{2}$ emissions: A revisited Environmental Kuznets Curve approach. Renewable and Sustainable Energy Reviews, 54, 838-45.

Chen, L., Thapa, B., \& Yan, W. (2018). The relationship between tourism, carbon dioxide emissions, and economic growth in the Yangtze River Delta, China. Sustainability, 10(7), 2118.

Chiu, C. L. \& Chang, T. C. (2009). What proportion of renewable energy supplies is needed to initially mitigate $\mathrm{CO}_{2}$ emissions in OECD member countries? Renewable and Sustainable Energy Reviews, 13(6), 1669-74.

Dicky, D. A., \& Fuller, W. A. (1979). Distribution of the Estimators for Autoregressive Time Series with a Unit Root. Journal of the American Statistical Association, 74, 427-31.

Dogan, E., \& Ozturk, I. (2017). The influence of renewable and non-renewable energy consumption and real income on $\mathrm{CO}_{2}$ emissions in the USA: Evidence from structural break tests. Environmental Science and Pollution Research, 24(11), 10846-54.

Dogan, E., \& Seker, F. (2016). The influence of real output, renewable and non-renewable energy, trade and financial development on carbon emissions in the top renewable energy countries. Renewable and Sustainable Energy Reviews, 60, 1074-85.

Dogan, E., Seker, F., \& Bulbul, S. (2017). Investigating the impacts of energy consumption, real GDP, tourism and trade on $\mathrm{CO}_{2}$ emissions by accounting for cross-sectional dependence: A panel study of OECD countries. Current Issues in Tourism, 20(16), 1701-19. 
Dwyer, L., Forsyth, P., Spurr, R., \& Hoque, S. (2010). Estimating the carbon footprint of Australian tourism. Journal of Sustainable Tourism, 18(3), 355-76.

EIA. (2017). International Energy Outlook. U.S. Energy Information Administration Website, September 14. https://www.eia.gov/outlooks/ieo/pdf/0484(2017).pdf (accessed July 6, 2019).

Gössling, S., Scott, D., \& Hall, C. M. (2013). Challenges of tourism in a low-carbon economy. Wiley interdisciplinary reviews: Climate change, 4(6), 525-38.

Grinsted, A., Moore, J. C., \& Jevrejeva, S. (2004). Application of the cross wavelet transform and wavelet coherence to geophysical time series. Nonlinear processes in geophysics, 11(5/6), $561-66$.

Ibrahiem, D. M. (2016). Environmental Kuznets curve: An empirical analysis for carbon dioxide emissions in Egypt. International Journal of Green Economics, 10(2), 136-50.

Isik, C., \& Magdalena, R. (2017). Investigation of the Relationship between Renewable Energy, Tourism Receipts and Economic Growth in Europe. Statıstıka-Statıstics And Economy Journal, 97(2), 85-94.

Isik, C., Doğan, E., \& Ongan, S. (2017). Analyzing the Tourism-Energy-Growth Nexus for the Top 10 Most-Visited Countries. Economies, 5(4), 1-13.

Isik, C., Dogru, T., \& Turk, E. S. (2017). Nexus of linear and non-linear relationships between tourism demand, renewable energy consumption, and economic growth: Theory and evidence. International Journal of Tourism Research, 20(1), 38-49.

Jalil, A. \& Mahmud, S. F. (2009). Environmental Kuznets curve for $\mathrm{CO}_{2}$ emissions: A cointegration analysis for China. Energy Policy, 37(12), 5167-72. 
Jayanthakumaran, K., Verma, R., \& Liu, Y. (2012). $\mathrm{CO}_{2}$ emissions, energy consumption, trade, and income: a comparative analysis of China and India. Energy Policy, 42, 450-60.

Johansen, S., \& Juselius, K. (1990). Maximum likelihood estimation and inference on cointegration with applications to the demand for money. Oxford Bulletin of Economics and Statistics, 52(2), 169-210.

Katircioglu, S. T. (2014). Testing the tourism-induced EKC hypothesis: The case of Singapore. Economic Modelling, 41, 383-91.

Kristoufek, L. (2015). What are the main drivers of the Bitcoin price? Evidence from wavelet coherence analysis. PloS ONE, 10(4), 1-15.

Kuo, K.C., Liu, M., \& Lai, S. L. (2012). Effect of tourism development on energy consumption, $\mathrm{CO}_{2}$ and economic growth in China. Advanced Materials Research, 524-527, 3380-83.

Lean, H. H., \& Smyth, R. (2010). $\mathrm{CO}_{2}$ emissions, electricity consumption and output in ASEAN. Applied Energy, 87(6), 1858-64.

Lee, J. W., \& Brahmasrene, T. (2013). Investigating the influence of tourism on economic growth and carbon emissions: Evidence from panel analysis of the European Union. Tourism Management, 38, 69-76.

Lenzen, M., Sun, Y. Y., Faturay, F., Ting, Y. P., Geschke, A., \& Malik, A. (2018). The carbon footprint of global tourism. Nature Climate Change, 8(6), 522-528.

León, C. J., Arana, J. E., \& Hernández Alemán, A. (2014). $\mathrm{CO}_{2}$ emissions and tourism in developed and less developed countries. Applied Economics Letters, 21, 1169-73.

Li, L., Li, J., Tang, L., \& Wang, S. (2019). Balancing Tourism's Economic Benefit and $\mathrm{CO}_{2}$ Emissions: An Insight from Input-Output and Tourism Satellite Account Analysis. Sustainability, 11(4), 1052. 
Lin, B., \& Moubarak, M. (2014). Renewable energy consumption - Economic growth nexus for China. Renewable and Sustainable Energy Reviews, 40, 111-17.

Liu, M., Lai, S. L., \& Kuok, C. (2012). Economic growth, energy consumption and tourism development in Taiwan: A Granger causality approach. Advanced Materials Research, $524-527,3376-9$.

Liu, Y., San Liang, X., \& Weisberg, R. H. (2007). Rectification of the bias in the wavelet power spectrum. Journal of Atmospheric and Oceanic Technology, 24(12), 2093-2102.

Mihanović, H., Orlić, M., \& Pasarić, Z. (2009). Diurnal thermocline oscillations are driven by tidal flow around an island in the Middle Adriatic. Journal of Marine Systems, 78, S157-68.

Mishra, S., Sharif, A., Khuntia, S., Meo, S. A., \& Khan, S. A. R. (2019). Does oil prices impede Islamic stock indices? Fresh insights from wavelet-based quantile-on-quantile approach. Resources Policy, 62, 292-304.

Mishra, S., Sinha, A., Sharif, A., \& Suki, N. M. (2019b). Dynamic linkages between tourism, transportation, growth and carbon emission in the USA: evidence from partial and multiple wavelet coherence. Current Issues in Tourism, 1-23.

Ng, E. K., \& Chan, J. C. (2012). Geophysical applications of partial wavelet coherence and multiple wavelet coherence. Journal of Atmospheric and Oceanic Technology, 29(12), $1845-53$.

Niu, S., Ding, Y., Niu, Y., Li, Y., \& Luo, G. (2011). Economic growth, energy conservation and emissions reduction: A comparative analysis based on panel data for 8 Asian-Pacific countries. Energy Policy, 39(4), 2121-31.

Ocal, O., \& Aslan, A. (2013). Renewable energy consumption - economic growth nexus in Turkey. Renewable and Sustainable Energy Reviews, 28, 494-99. 
Othman, N., Mohamed, S., \& Aziz, F. (2012). Tourism activities and its impact on environmental sustainability in coastal areas. Paper presented at the 2nd international conference on Economics, Trade and Development, Singapore.

Ozturk, I. (2010). A literature survey on energy-growth nexus. Energy policy, 38(1), 340-49.

Ozturk, I. (2016). The relationships among tourism development, energy demand, and growth factors in developed and developing countries. International Journal of Sustainable Development \& World Ecology, 23(2), 122-31.

Paramati, S. R., Shahbaz, M., \& Alam, Md. S. (2017). Does tourism degrade environmental quality? A comparative study of Eastern and Western European Union. Transportation Research Part D: Transport and Environment, 50, 1-13.

Phillips, P. B., \& Perron, P. (1988). "Testing for a Unit Root in Time Series Regression." Biometrika, 75(2), 335-46.

Raza, S. A., Shah, N., \& Sharif, A. (2019). Time frequency relationship between energy consumption, economic growth and environmental degradation in the United States: Evidence from transportation sector. Energy, 173, 706-720.

Raza, S. A., Sharif, A., Wong, W. K., \& Abd Karim, M. Z. (2017). Tourism development and environmental degradation in the United States: evidence from the wavelet-based analysis. Current Issues in Tourism, 20(16), 1768-90.

Riti, J. S., Song, D., Shu, Y., \& Kamah, M. (2017). Decoupling $\mathrm{CO}_{2}$ emission and economic growth in China: Is their consistency in estimation results in analyzing environmental Kuznets curve? Journal of Cleaner Production, 168, 1217-29. 
Robaina-Alves, M., Moutinho, V., \& Costa, R. (2016). Change in energy-related $\mathrm{CO}_{2}$ (carbon dioxide) emissions in Portuguese tourism: A decomposition analysis from 2000 to 2008 . Journal of Cleaner Production, 111, 520-28.

Rossello-Batle, B., Moia, A., Cladera, A., \& Martinez, V. (2010). Energy use, $\mathrm{CO}_{2}$ emissions and waste throughout the life cycle of a sample of hotels in the Balearic Islands. Energy and Buildings, 42(4), 547-58.

Rua, A., \& Nunes, L. C. (2009). International comovement of stock market returns: A wavelet analysis. Journal of Empirical Finance, 16(4), 632-639.

Say, N. P., \& Yucel, M. (2006). Energy consumption and CO2 emissions in Turkey: empirical analysis and future projection based on an economic growth. Energy Policy, 34(18), 387076.

Sebri, M., \& Ben-Salha, O. (2014). On the causal dynamics between economic growth, renewable energy consumption, $\mathrm{CO}_{2}$ emissions, and trade openness: Fresh evidence from BRICS countries. Renewable and Sustainable Energy Reviews, 39, 14-23.

Sekrafi, H., \& Sghaier, A. (2018). Exploring the relationship between tourism development, energy consumption, and carbon emissions: A case study of Tunisia. International Journal of Social Ecology and Sustainable Development, 9(1), 26-39.

Shahbaz, M., \& Sinha, A. (2019). Environmental Kuznets curve for $\mathrm{CO}_{2}$ emissions: a literature survey. Journal of Economic Studies, 46(1), 106-168.

Shahbaz, M., Farhani, S., \& Ozturk, I. (2015). Do coal consumption and industrial development increase environmental degradation in China and India? Environmental Science and Pollution Research, 22(5), 3895-907. 
Shahbaz, M., Khraief, N., Uddin, G. S., \& Ozturk, I. (2014). Environmental Kuznets curve in an open economy: Bounds testing and causality analysis for Tunisia. Renewable, and Sustainable Energy Reviews, 34, 325-36.

Shahzad, S. J. H., Kumar, R. R., Zakaria, M., \& Hurr, M. (2017). Carbon emission, energy consumption, trade openness and financial development in Pakistan: A revisit. Renewable and Sustainable Energy Reviews, 70, 185-92.

Sharif, A., \& Afshan, S. (2016). Tourism development and real effective exchange rate revisited by wavelet based analysis: Evidence from France. Journal of Finance and Economics Research, 1(2), 101-118.

Sharif, A., Afshan, S., \& Nisha, N. (2017). Impact of tourism on $\mathrm{CO}_{2}$ emission: Evidence from Pakistan. Asia Pacific Journal of Tourism Research, 22(4), 408-21.

Sharif, A., Afshan, S., \& Qureshi, M. A. (2019). Idolization and ramification between globalization and ecological footprints: evidence from quantile-on-quantile approach. Environmental Science and Pollution Research, 26(11), 11191-11211.

Sharif, A., Saha, S., \& Loganathan, N. (2017). Does tourism sustain economic growth? Waveletbased evidence from the United States. Tourism Analysis, 22(4), 467-482.

Sharif, A., Shahbaz, M., \& Hille, E. (2019). The Transportation-growth nexus in USA: Fresh insights from pre-post global crisis period. Transportation Research Part A: Policy and Practice, 121, 108-121.

Shuxin, W., Genxu, W., \& Yiping, F. (2016). Factors influencing the energy efficiency of tourism transport in China. Journal of Resources and Ecology, 7(4), 246-254. 
Sinha, A., Shahbaz, M., \& Balsalobre, D. (2017). Exploring the relationship between energy usage segregation and environmental degradation in N-11 countries." Journal of Cleaner Production, 168, 1217-29.

Solarin, S. A. (2014). Tourist arrivals and macroeconomic determinants of $\mathrm{CO}_{2}$ emissions in Malaysia. International Journal of Tourism and Hospitality Research, 25(2), 228-241.

Tang, C. F., \& Tan, B. W. (2015). The impact of energy consumption, income and foreign direct investment on carbon dioxide emissions in Vietnam. Energy, 79, 447-54.

Tang, M., \& Ge, S. (2018). Accounting for carbon emissions associated with tourism-related consumption. Tourism Economics, 24(5), 510-525.

Tang, Z., Shang, J., Shi, C., Liu, Z., \& Bi, K. (2014). Decoupling indicators of $\mathrm{CO}_{2}$ emissions from the tourism industry in China: 1990-2012. Ecological Indicators, 46, 390-397.

Tiwari, A. K., Bhanja, N., Dar, A. B., \& Islam, F. (2015). Time-frequency relationship between share prices and exchange rates in India: Evidence from continuous wavelets. Empirical Economics, 48(2), 699-714.

Tiwari, A. K., Ozturk, I., \& Aruna, M. (2013). Tourism, energy consumption and climate change in OECD countries. International Journal of Energy Economics and Policy, 3(3), 247-61.

Torrence, C., \& Compo, G. P. (1998). A practical guide to wavelet analysis. Bulletin of the American Meteorological Society, 79(1), 61-78.

Torrence, C., \& Webster, P. J. (1999). "Interdecadal changes in the ENSO-monsoon system". Journal of Climate, 12(8), 2679-90.

UNEP (2008). Climate Change and Tourism: Responding to Global Challenges. World Tourism Organization, Madrid, Spain. 
UNWTO (2018). UNWTO-WTCF City Tourism Performance Research: Beijing Case Study. Working Paper.

UNWTO. (2017). Tourism Highlights. UNWTO Website. https://www.eunwto.org/doi/pdf/10.18111/9789284419029 (accessed July 6, 2019).

Veleda, D., Montagne, R., \& Araujo, M. (2012). Cross-wavelet bias corrected by normalizing scales. Journal of Atmospheric and Oceanic Technology, 29(9), 1401-1408.

WTTC. (2018). Travel and Tourism Economic Impact 2018 China. WTTC Website. https://www.wttc.org/-/media/files/reports/economic-impact-research/countries2018/china2018.pdf(accessed December 12, 2018).

Wu, P., \& Shi, P. (2011). "An estimation of energy consumption and $\mathrm{CO}_{2}$ emissions in tourism sector of China." Journal of Geographical Sciences, 21(4), 733-45.

Zaman, K., Khan, M. M., \& Ahmad, M. (2011). Exploring the relationship between tourism development indicators and carbon emissions: A case study of Pakistan. World Applied Sciences Journal, 15(5), 690-701.

Zaman, K., Shahbaz, M., Loganathan, N., \& Raza, S. A. (2016). Tourism development, energy consumption and environmental Kuznets curve: Trivariate analysis in the panel of developed and developing countries. Tourism Management, 54, 275-83.

Zeshan, M., \& Ahmed, V. (2013). Energy, environment and growth nexus in South Asia. Environment Development, and Sustainability, 15(6), 1465-75.

Zhang, L., \& Gao, J. (2016). Exploring the effects of international tourism on China's economic growth, energy consumption, and environmental pollution: Evidence from a regional panel analysis. Renewable and Sustainable Energy Reviews, 53, 225-34. 
Zoundi, Z. (2017). $\mathrm{CO}_{2}$ emissions, renewable energy and the environmental Kuznets curve, a panel cointegration approach. Renewable and Sustainable Energy Reviews, 72, 1067-75. 
Table 1. Descriptive statistics

\begin{tabular}{lrrrr}
\hline & \multicolumn{1}{c}{ TOR } & \multicolumn{1}{c}{ RENEW } & \multicolumn{1}{c}{ ENC } & \multicolumn{1}{c}{ CO2 } \\
\hline Mean & 6759.656 & 211489.900 & 1112.545 & 4530932.000 \\
Maximum & 15053.940 & 306458.300 & 2236.730 & 10291927.000 \\
Minimum & 168.234 & 174584.900 & 537.175 & 1196194.000 \\
Std. Dev. & 5129.251 & 24102.240 & 555.444 & 3158145.000 \\
Skewness & 0.184 & 0.722 & 0.842 & 0.826 \\
Kurtosis & 1.451 & 1.828 & 2.154 & 2.159 \\
Jarque-Bera & 24.436 & 61.562 & 6.214 & 6.008 \\
Probability & 0.000 & 0.000 & 0.045 & 0.050 \\
\hline Correlation Matrix & \multicolumn{5}{c}{} & & \\
\hline TOR & 1 & & & \\
RENEW & $0.619 *$ & & & \\
& $(0.000)$ & & & \\
ENC & $0.926^{*}$ & $-0.555^{*}$ & & \\
& $(0.000)$ & $(0.000)$ & & \\
CO2 & $0.931^{*}$ & $-0.632^{*}$ & $0.992^{*}$ & \\
& $(0.000)$ & $(0.000)$ & $(0.000)$ & \\
\hline
\end{tabular}

Note: * denotes the rejection of the null hypothesis at the $1 \%$ significance level 
TOR

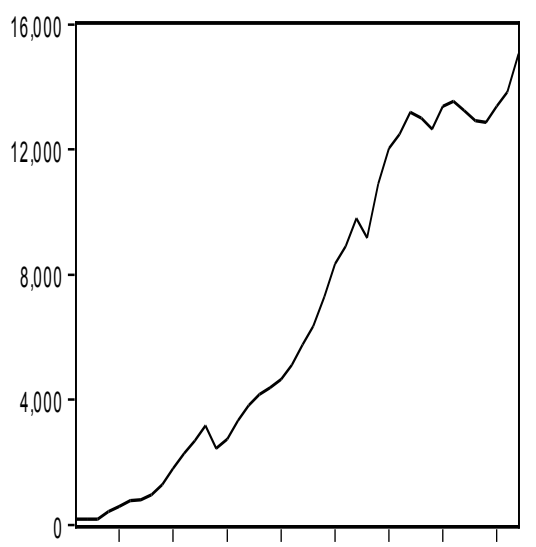

$1980 \quad 1995 \quad 1990 \quad 1995 \quad 2000 \quad 2005 \quad 2010 \quad 2015$

RENEN

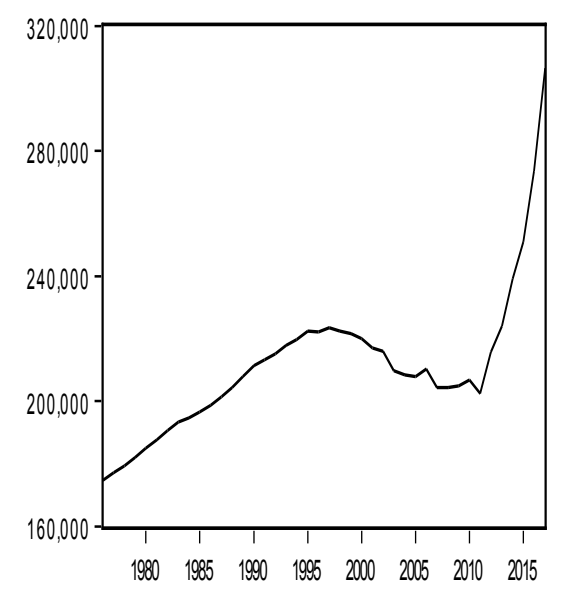

Natural log Return (TOR)

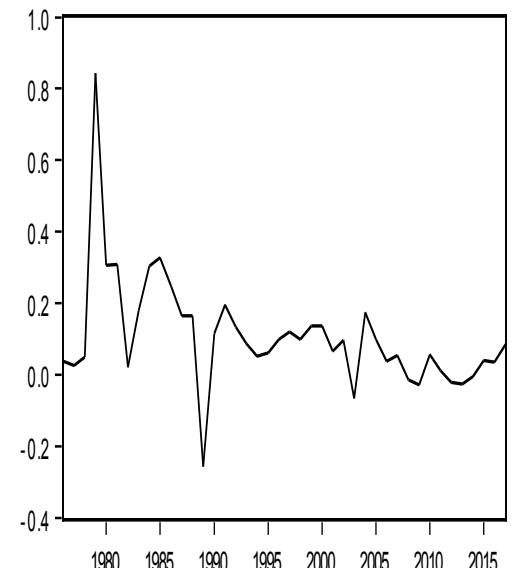

$109001995 \quad 19901995 \quad 2000 \quad 2005 \quad 2010 \quad 2015$
ENC

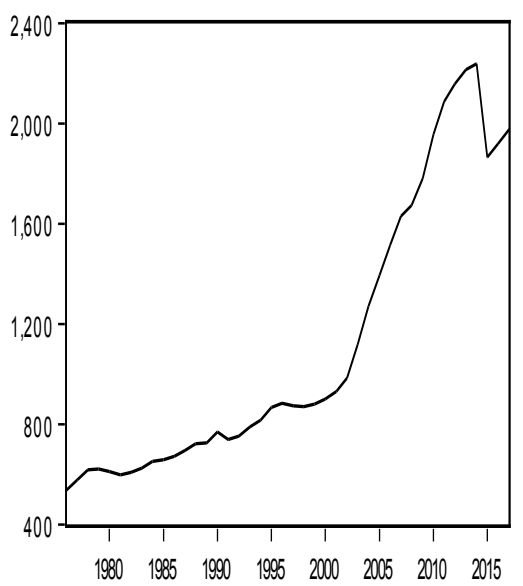

$\mathrm{CO} 2$

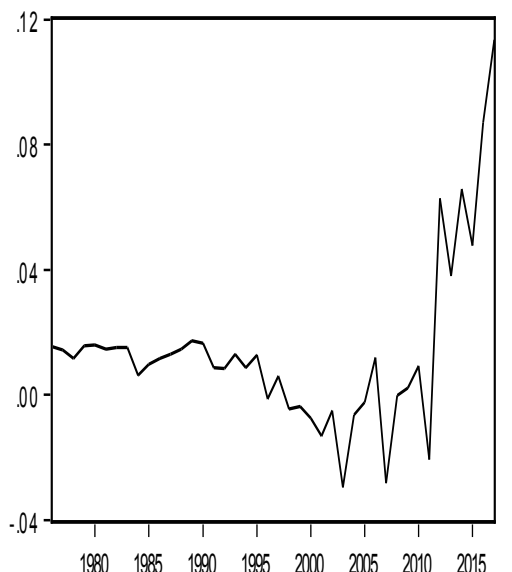

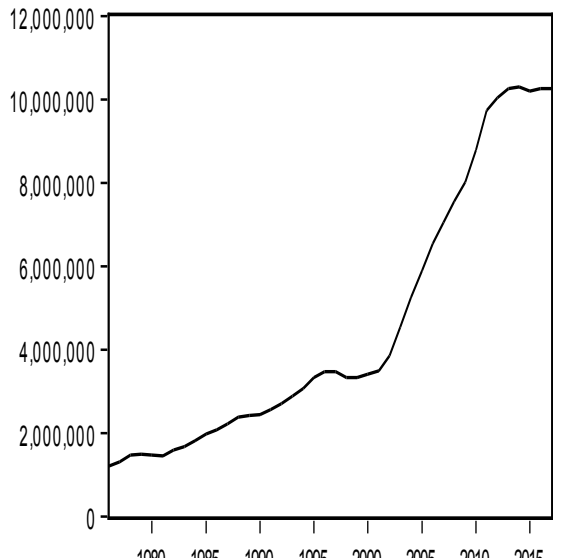

Natural log Return (ENC)

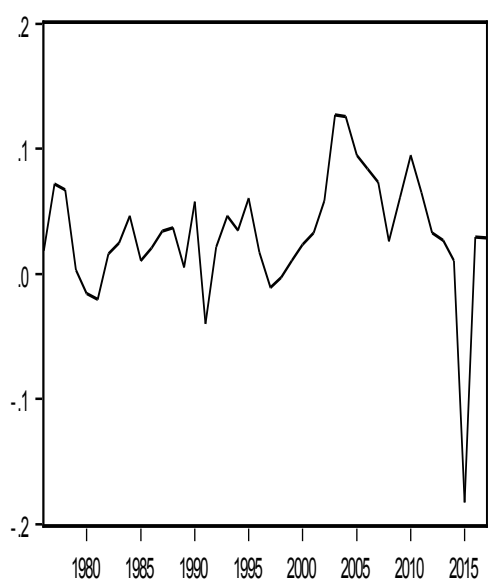

Natural log Return (CO2)

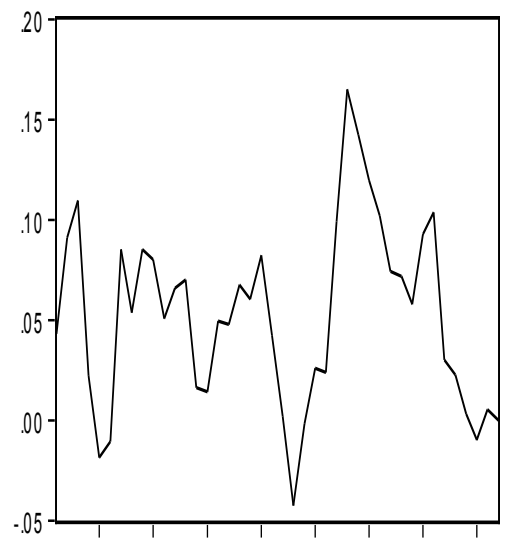

Figure 1: Actual and Natural log return series of TOR, ENC, RENEW \& $\mathrm{CO} 2$ 


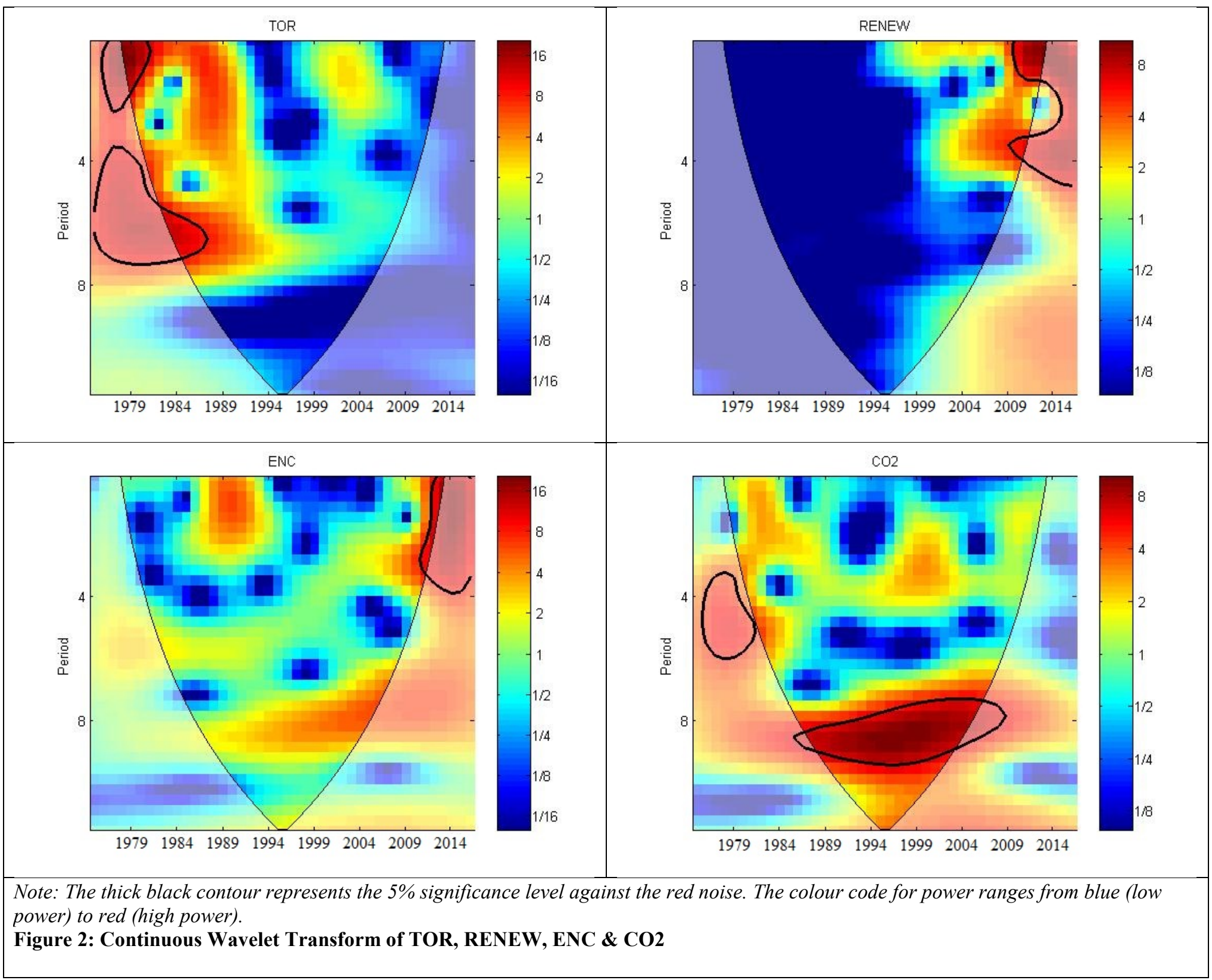




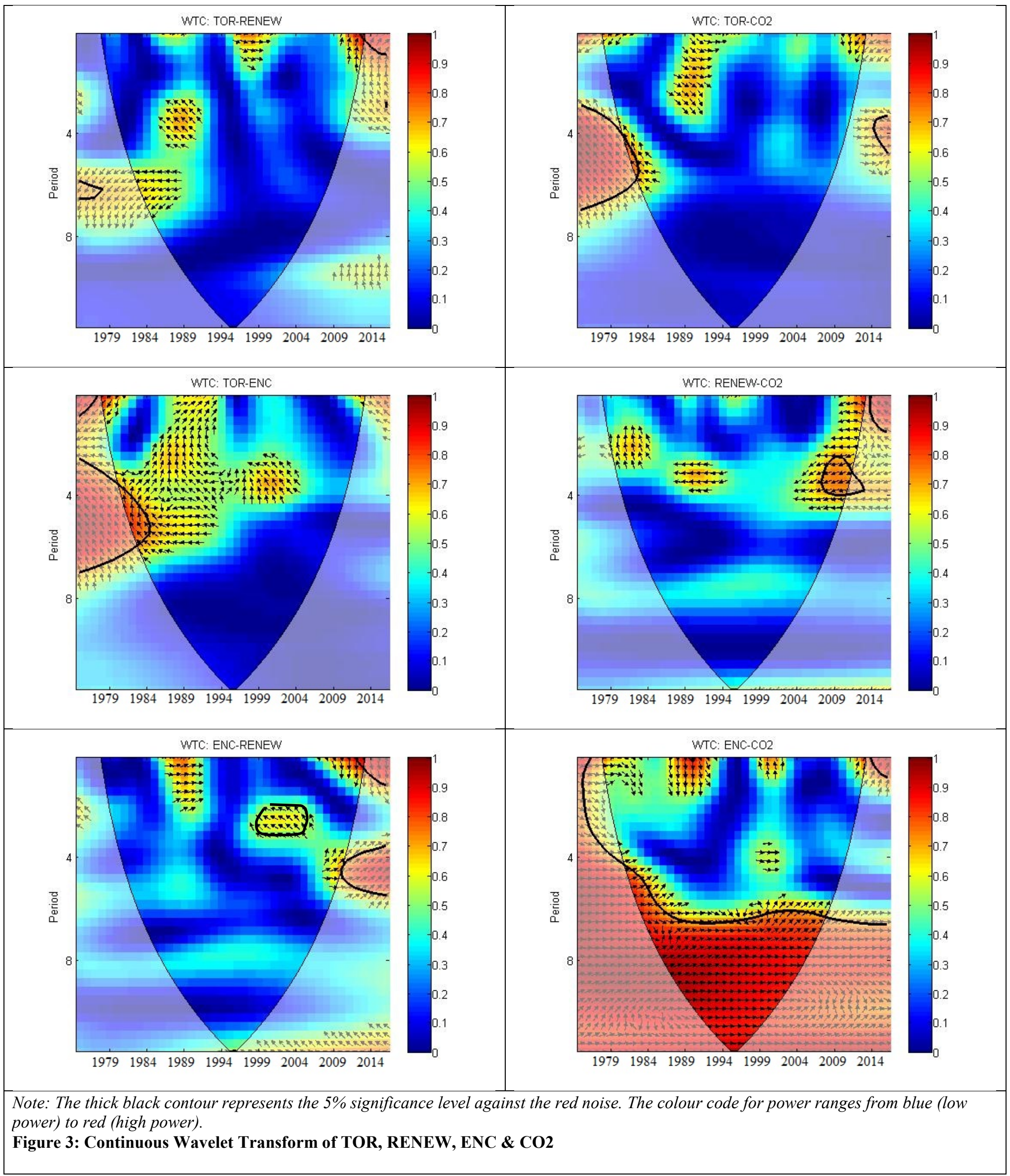




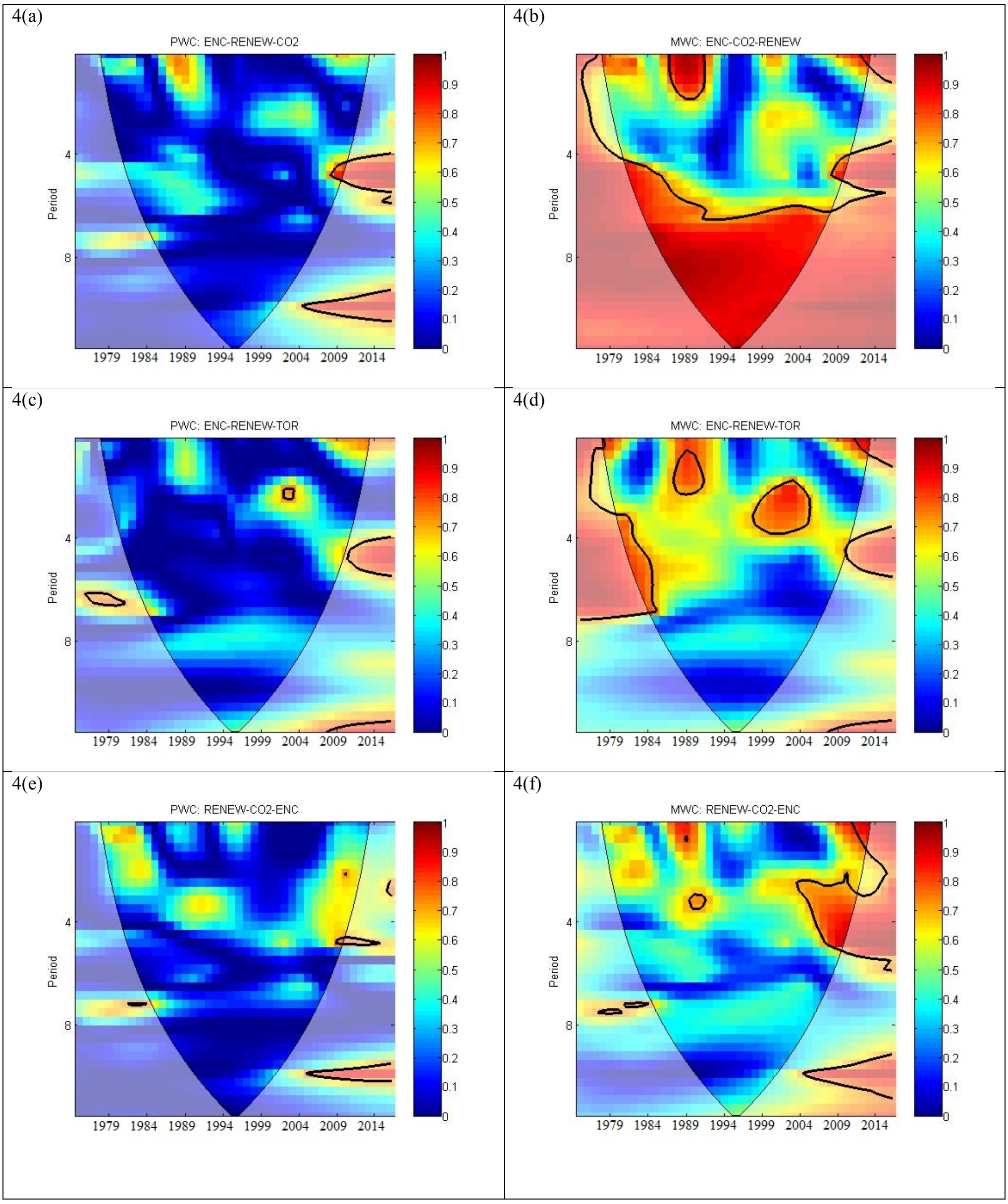




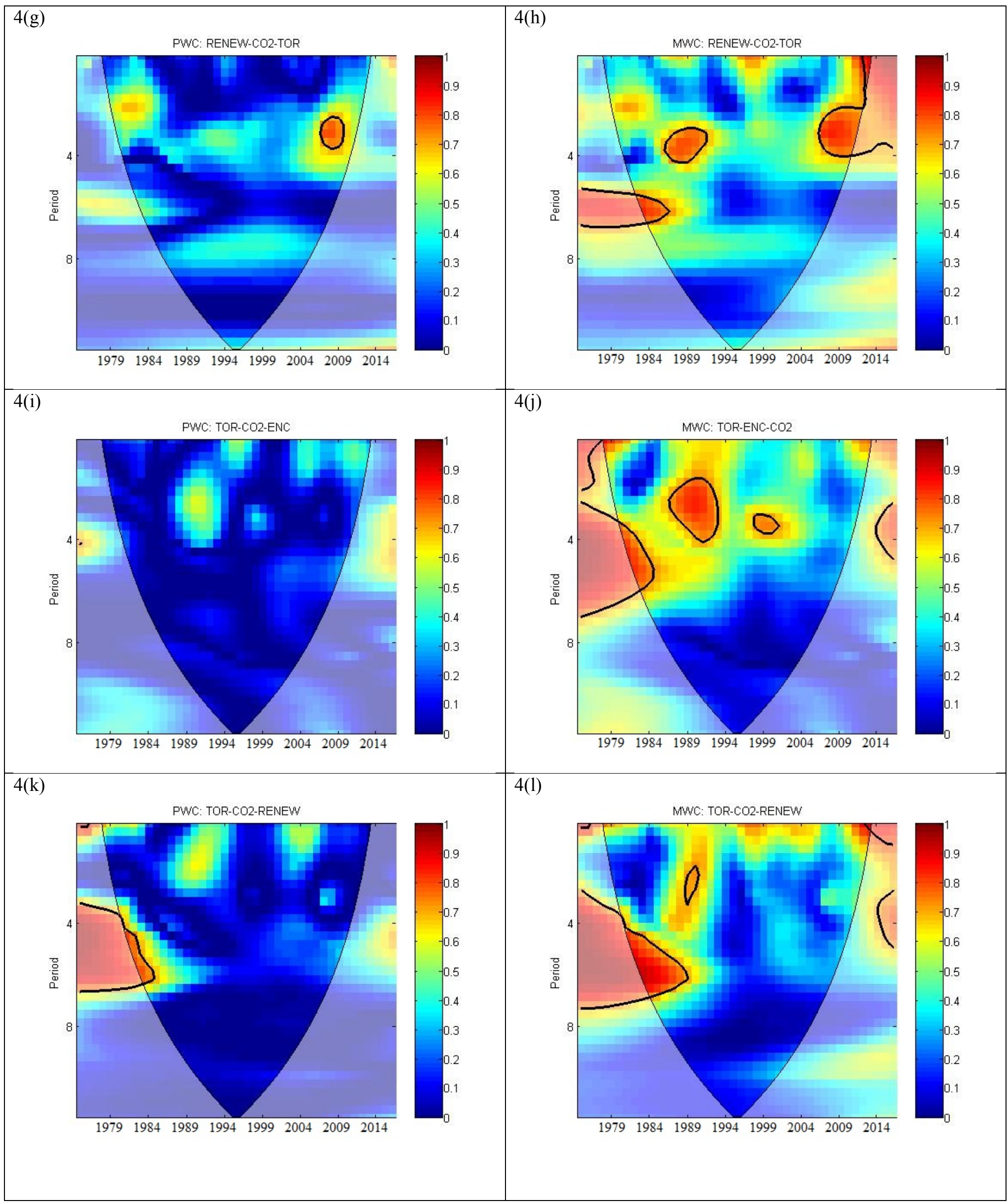




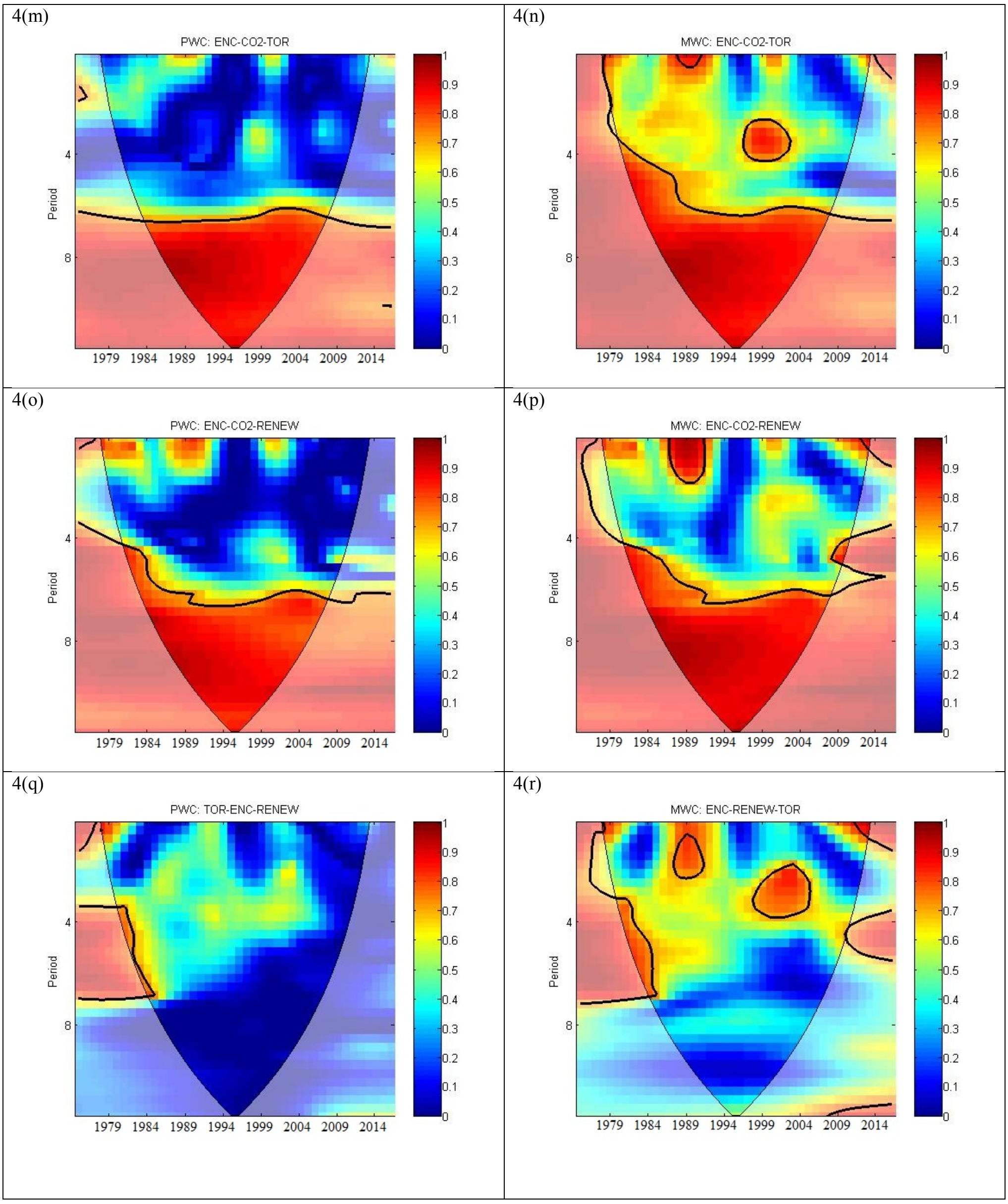


$4(s)$

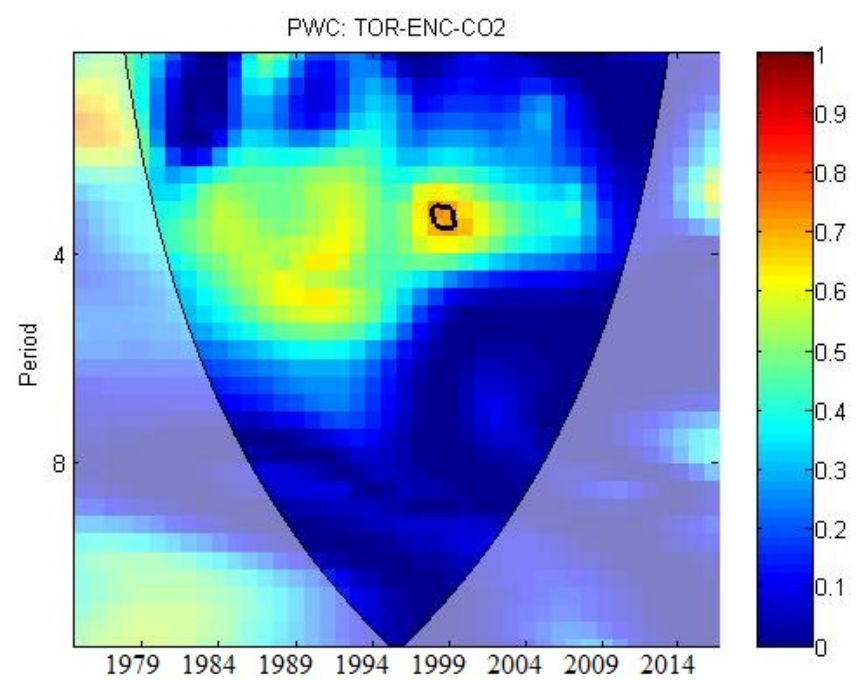

$4(u)$

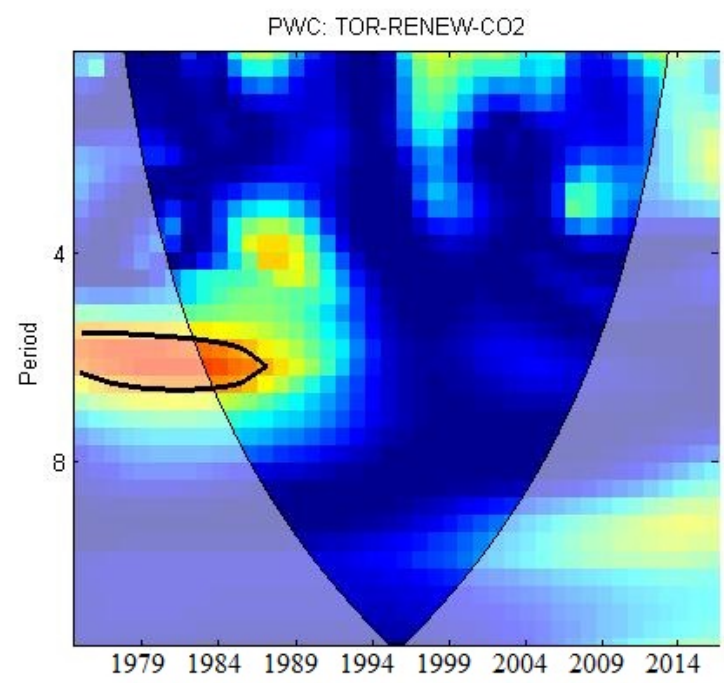

$4(\mathrm{w})$

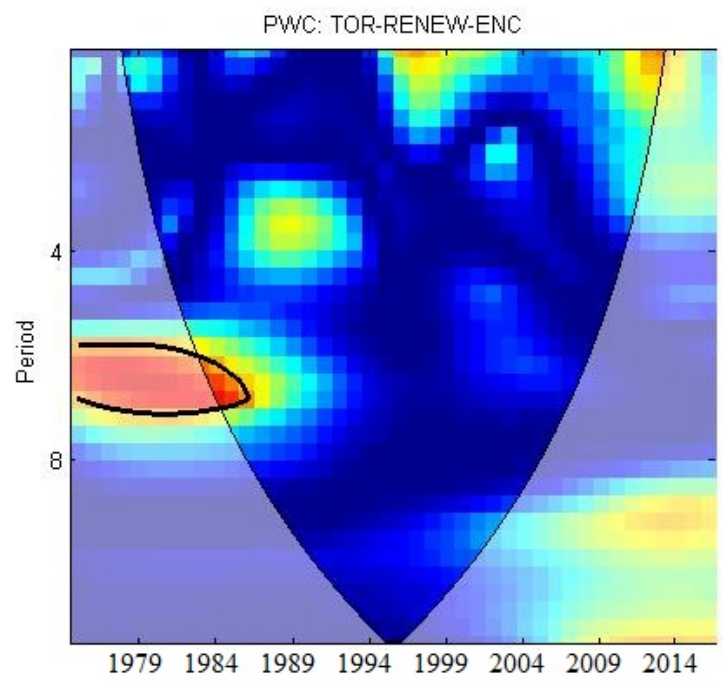

$4(\mathrm{t})$

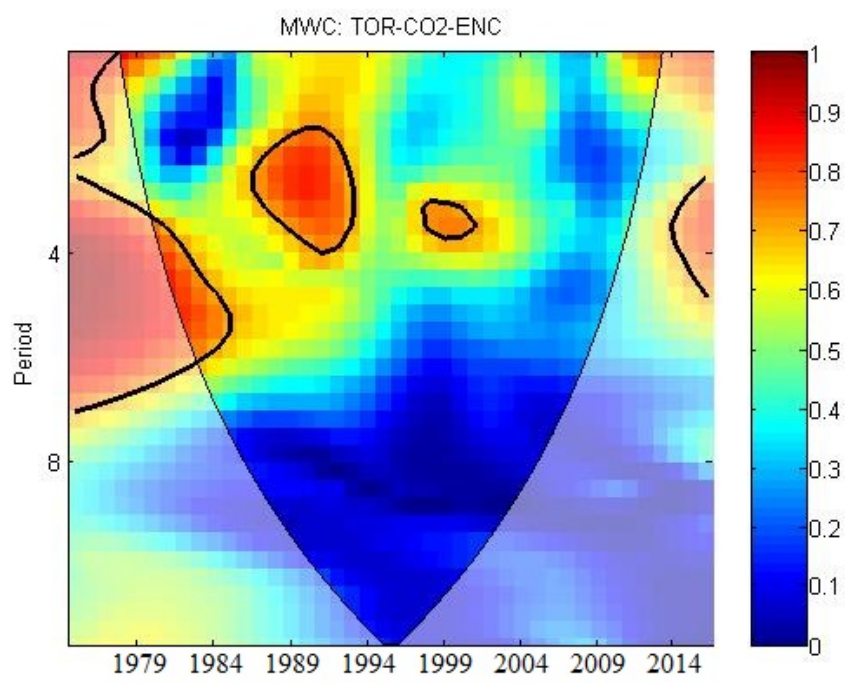

$4(\mathrm{v})$

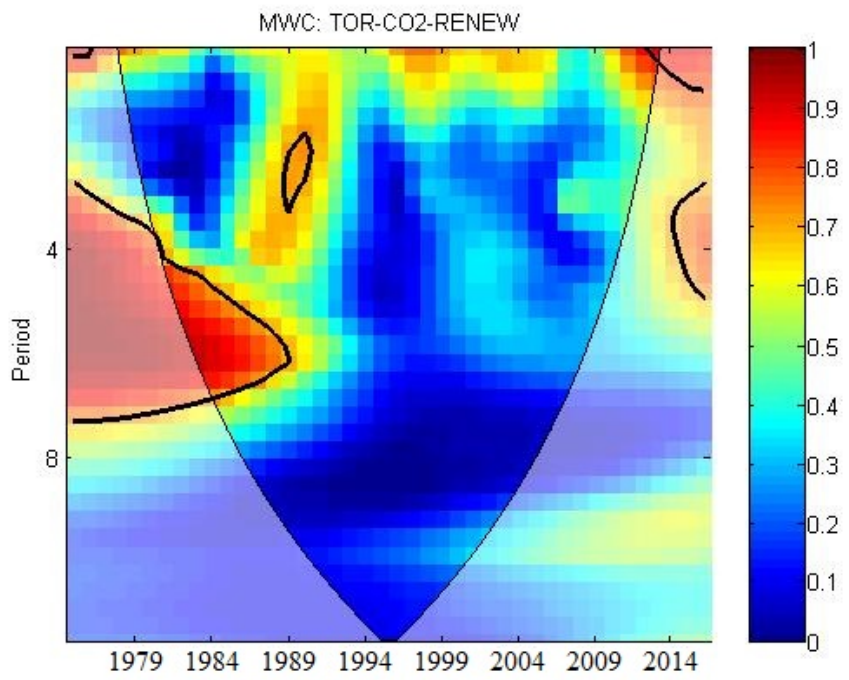

$4(\mathrm{x})$

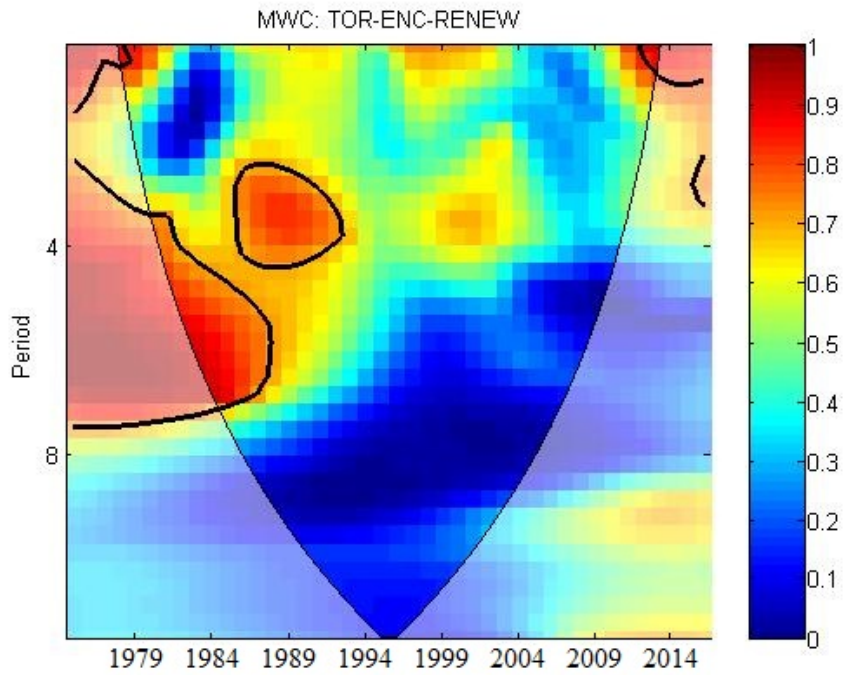


